\title{
Prediction of preterm birth by evaluating the fetal adrenal gland volume and blood flow: a pilot study
}

\author{
Ali Saber Ali, Mostafa Hussein, Ahmed N. Fetih, Abdelghafar M. Ahmed, Ahmed M. Abbas*
}

Department of Obstetrics and Gynecology, Faculty of Medicine, Assiut University, Egypt

Received: 04 August 2018

Accepted: 29 August 2018

\section{*Correspondence:}

Dr. Ahmed M. Abbas,

E-mail: bmr90@hotmail.com

Copyright: (C) the author(s), publisher and licensee Medip Academy. This is an open-access article distributed under the terms of the Creative Commons Attribution Non-Commercial License, which permits unrestricted non-commercial use, distribution, and reproduction in any medium, provided the original work is properly cited.

\begin{abstract}
Background: The aim of the current study was to estimate the risk of preterm birth (delivery $<37$ weeks of gestation) by evaluating the fetal adrenal gland volume and blood flow at Women's Health Hospital, Assiut University, Egypt. Methods: A pilot prospective cohort study included pregnant women presented to our hospital with threatened preterm labor between December 2016 and May 2018. All women were recruited consecutively at the emergency unit of Women's Health Hospital at Assiut University. The fetal adrenal gland volume was assessed using 3-dimensional images of the fetal adrenal with the aid of Virtual Organ Computer-Aided Analysis (VOCAL) software. Doppler evaluation of the fetal adrenal blood vessels was carried out. The RI, PI and S/D ratio was calculated for every case. The neonatal outcomes at delivery were assessed and compared with respect to the duration of actual delivery from the time of evaluation. The obtained data were analyzed by SPSS software (version 22.0) and $\mathrm{p}<0.05$ was taken as the significant level.

Results: The study included 30 pregnant women at the final analysis. Women were classified according to the time of actual delivery into two groups. Group (I, n=13) those who delivered within 7 days and group (II, n=17) those who delivered 7 days or more. No difference between both groups regarding the baseline characteristics. No difference regarding the mode of delivery $(\mathrm{p}=0.708)$. All Doppler indices were statistically in-different between both groups. The fetal adrenal gland volume was significantly lower in group II than group I ( $\mathrm{p}=0.001)$. On ROC analysis, the area under the curve (AUC) for prediction of preterm birth based on the fetal adrenal gland volume was $(\mathrm{AUC}=0.873$ ). The ROC curve shows that the best cut off value using the volume was $\geq 0.461$ with $76.92 \%$ sensitivity and $88.24 \%$ specificity for prediction of preterm birth with an overall accuracy of $83.3 \%$.

Conclusions: Fetal adrenal gland volume was identified as a significant predictor of delivery in pregnant women who had spontaneous preterm births with intact membranes.
\end{abstract}

Keywords: Adrenal gland, Doppler, Preterm birth, Vocal

\section{INTRODUCTION}

Preterm birth continues to be a major public health problem with lasting family and societal repercussions. ${ }^{1}$ Despite tremendous research effort, prevention strategies have failed, and the prevalence of preterm birth in the United States reached $12.3 \%$ in $2003 .^{2}$ Prematurity causes
$70 \%$ of fetal/neonatal deaths. $11.4 \%$ of births are at $<37$ weeks' gestation. The rate of prematurity increases dramatically with the number of fetuses - singletons $10 \%$; twins $54.9 \%$; and triplets $93.6 \%$. The etiology of most preterm births remains elusive and is likely multifactorial, with many pathological-physiological pathways being involved, such as excessive stretching, oxidative stress, 
decidual hemorrhage, and infection. To wit, the past efforts to reduce prematurity may have failed because each causative pathway requires a distinct therapeutic intervention. ${ }^{3}$ Of the multiple mechanisms implicated, it was suggested that the fetus may be in control of the timing of birth via activation of its own hypothalamicpituitary-adrenal axis. ${ }^{4}$ Current thinking is that placental corticotropin-releasing hormone (CRH) promotes activation of the fetal hypothalamic-pituitary-adrenal axis, which in turn stimulates the production of cortisol by the fetal adrenal gland, followed by activation of a cascade of events that suppress the mechanisms responsible for uterine quiescence. ${ }^{5}$

This paradigm is supported by the observational evidence that, at term, before the onset of labor, the weight of the fetal adrenal gland is the same as that of the adult adrenal gland. ${ }^{6}$ Further, the observation that the fetal adrenal gland increases in size in pregnancies complicated by preterm birth makes it extremely likely that the fetus is indeed an active participant in the process of premature parturition. $^{7}$

The usefulness of fetal adrenal gland volume as a disease marker that can aid development of new strategies for the prediction of preterm birth has not been previously investigated. ${ }^{8}$ Fetal adrenal artery Doppler velocimetry was identified as a good predictor of delivery in pregnant women who had spontaneous preterm births with intact membranes.

Therefore, the aim of the current study was to estimate the risk of preterm birth (delivery <37 weeks of gestation) by evaluating the fetal adrenal gland volume and blood flow.

\section{METHODS}

A pilot prospective cohort study included pregnant women presented to our hospital with threatened preterm labor between December 2016 and May 2018. All women were recruited consecutively at the emergency unit of Women's Health Hospital at Assiut University.

\section{Inclusion criteria}

- Women with singleton fetus less than 37 weeks of gestation diagnosed to have threatened preterm labor according to ACOG (2013): Presence of uterine contraction (at least 4 in $20 \mathrm{~min}$ or 8 in $60 \mathrm{~min}$ ), Cervical effacement $<80 \%$, Cervical dilatation $<1$ $\mathrm{cm}^{9}$

\section{Exclusion criteria}

- Suspected fetal growth restriction (sonographic fetal weight less than the 10th percentile for gestational age),

- Maternal medical complications (hypertension, preeclampsia, diabetes, thyroid or adrenal diseases),
- Presence of fetal heart rate abnormalities at enrollment (bradycardia or prolonged variable decelerations).

- Preterm PROM

- Placenta previa

- Lower urinary tract infection or genital infection

- Fetal congenital anomaly.

Data were recorded in a sheet include hospital number of the case, age, education, residence, occupation, consanguinity, gravidity, parity, previous pregnancy complications, gestational age, height, weight, history of drug usage and occupation, education, special habits of her husband. Time between fetal gland evaluation and delivery categorized into: delivery within 7 days (Group I) and delivery later than 7 days (Group II).

\section{Measure fetal adrenal gland blood flow}

The renal artery was visualized in a longitudinal scan of the fetal abdomen where the renal arteries originate from the descending aorta. Flow velocity waveforms were registered from the right or left main trunk before they branch to the renal pelvis. We register PI, RI, S/D of every case then Labor, and delivery outcomes were assessed and compared with respect to adrenal Doppler. A centrally located artery entering the adrenal gland where the adrenal vein leaves it, and coursing towards the lateral edge of the gland was visualized within the hyperechogenic area of the adrenal in an obliquetransverse scan of the fetal abdomen just above the kidneys. This was assumed to be the middle adrenal artery. Blood flow assessments were made at the proximal end of the middle adrenal artery just after it entered the organ. Either the right or left adrenal artery was the subject of study.

\section{Measure adrenal gland volume by $3 D$ ultrasound}

Volumetric measurements of the fetal adrenal gland at their indicated antenatal sonogram. 3-dimensional images of the fetal adrenal were acquired, and volumes were calculated using Virtual Organ Computer-Aided Analysis (VOCAL) software. The neonatal outcomes at delivery were assessed and compared with respect to the duration of actual delivery from the time of evaluation

\section{Statistical analysis}

Data were processed using Statistical Package of Social Sciences version 22.0 (SPSS version 22.0 Inc., Chicago, IL, USA). Quantitative data were expressed as means \pm standard deviation (SD) as appropriate. Qualitative data was expressed as frequency (numbers) and percentages. A probability value ( $\mathrm{p}$-value) $<0.05$ was considered statistically significant. ROC analysis was performed and the area under the curve (AUC) was estimated for prediction of preterm birth based on the fetal adrenal gland volume to detect the sensitivity and specificity of the best cut off value using the volume of adrenal gland. 


\section{RESULTS}

The study included 30 pregnant women at the final analysis. Group (I) $n=13$ those who delivered within 7 days and group (II) $\mathrm{n}=17$ those who delivered 7 days or more. No difference between both groups regarding the baseline characteristics (Table 1).

Table 1: Baseline characteristics of the study participants.

\begin{tabular}{|c|c|c|c|}
\hline Variables & Group $\mathrm{I}<7$ days $(\mathrm{n}=13)$ & Group II $\geq 7$ days $(n=17)$ & P-value \\
\hline Age (Years) & $27.31 \pm 7.15$ & $25.88 \pm 5.15$ & 0.675 \\
\hline Parity & $1.00 \pm 1.22$ & $1.65 \pm 1.84$ & 0.371 \\
\hline Gestational age & $33.28 \pm 2.52$ & $33.21 \pm 2.77$ & 0.921 \\
\hline \multicolumn{4}{|l|}{ Occupation } \\
\hline Working & $10(76.9 \%)$ & $14(82.4 \%)$ & \multirow[t]{2}{*}{0.713} \\
\hline Housewife & $3(23.1 \%)$ & $3(17.6 \%)$ & \\
\hline \multicolumn{4}{|l|}{ Education } \\
\hline Illiterate & $2(15.4 \%)$ & $3(17.6 \%)$ & \multirow[t]{2}{*}{0.869} \\
\hline OLiterate & $11(84.6 \%)$ & $14(82.4 \%)$ & \\
\hline \multicolumn{3}{|c|}{ Mode of delivery } & \multirow{3}{*}{0.708} \\
\hline Vaginal & $9(69.2 \%)$ & $10(58.8 \%)$ & \\
\hline $\mathrm{CS}$ & $4(30.8 \%)$ & $7(41.2 \%)$ & \\
\hline
\end{tabular}

Table 2: Fetal adrenal gland evaluation in both groups.

\begin{tabular}{|c|c|c|c|}
\hline Variables & Group $I<7$ days $(n=13)$ & Group II $\geq 7$ days $(n=17)$ & P-value \\
\hline \multicolumn{4}{|c|}{ 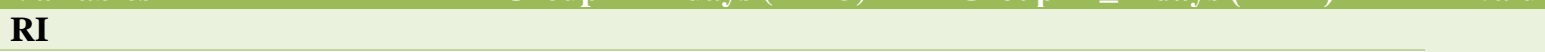 } \\
\hline Mean \pm SD & $0.69 \pm 0.08$ & $0.70 \pm 0.12$ & \multirow{2}{*}{0.850} \\
\hline Range & $0.6-0.8$ & $0.5-0.9$ & \\
\hline \multicolumn{3}{|l|}{ PI } & \multirow{3}{*}{0.950} \\
\hline Mean \pm SD & $1.44 \pm 0.39$ & $1.36 \pm 0.39$ & \\
\hline Range & $1.1-2.2$ & $0.7-2.1$ & \\
\hline \multicolumn{3}{|l|}{ S/D } & \multirow{3}{*}{0.675} \\
\hline Mean \pm SD & $3.59 \pm 0.84$ & $3.73 \pm 0.93$ & \\
\hline Range & $2.7-4.8$ & $1.8-4.8$ & \\
\hline \multicolumn{3}{|c|}{ Fetal adrenal volume: } & \multirow{3}{*}{$0.001 *$} \\
\hline Mean \pm SD & $0.65 \pm 0.21$ & $0.36 \pm 0.13$ & \\
\hline Range & $0.21-0.96$ & $0.17-0.70$ & \\
\hline
\end{tabular}

* Statistical significant difference

Table 3: The neonatal outcomes in both groups.

\begin{tabular}{|c|c|c|c|}
\hline & \multicolumn{2}{|l|}{ Time of delivery } & \multirow{2}{*}{ P-value } \\
\hline & $<7$ days $(n=13)$ & $\geq 7$ days $(n=17)$ & \\
\hline \multicolumn{3}{|c|}{ APGAR score 1 m } & \multirow{3}{*}{0.176} \\
\hline Mean \pm SD & $7.08 \pm 2.10$ & $8.12 \pm 2.18$ & \\
\hline Range & $4.0-10.0$ & $4.0-10.0$ & \\
\hline \multicolumn{3}{|c|}{ APGAR score 5 m } & \multirow{3}{*}{0.909} \\
\hline Mean \pm SD & $9.54 \pm 0.88$ & $9.41 \pm 1.18$ & \\
\hline Range & $8.0-10.0$ & $6.0-10.0$ & \\
\hline \multicolumn{3}{|c|}{ Need resuscitation } & \multirow{3}{*}{0.708} \\
\hline Yes & $4(30.8 \%)$ & $7(41.2 \%)$ & \\
\hline No & $9(69.2 \%)$ & $10(58.8 \%)$ & \\
\hline \multicolumn{3}{|c|}{ Need for NICU } & \multirow{3}{*}{0.713} \\
\hline Yes & $3(23.1 \%)$ & $3(17.6 \%)$ & \\
\hline No & $10(76.9 \%)$ & $14(82.4 \%)$ & \\
\hline \multicolumn{3}{|c|}{ Body weight } & \multirow{3}{*}{0.414} \\
\hline Mean \pm SD & $2353.85 \pm 683.34$ & $2513.29 \pm 733.95$ & \\
\hline Range & $1120.0-3220.0$ & $1380.0-3400.0$ & \\
\hline
\end{tabular}


Age parity, occupation, education and gestational age at inclusion were comparable between both groups. No difference regarding the mode of delivery, $69.2 \%$ in group I versus $58.8 \%$ in group II delivered vaginally $(\mathrm{p}=0.708)$.

All Doppler indices (RI, PI, S/D) were statistically indifferent between both groups $\mathrm{p}=0.850,0.950,0.675$, respectively) (Table 2). The fetal adrenal gland volume was significantly lower in group II than group I (0.36 \pm 0.13 vs. $0.65 \pm 0.21$ respectively, $\mathrm{p}=0.001$ ).

Table 3 shows similar neonatal outcomes in both groups ( $\mathrm{p}>0.05)$. Apgar score at 1 and 5 minutes were comparable between both groups $(p=0.176,0.909$ respectively).

On ROC analysis, the area under the curve (AUC) for prediction of preterm birth based on the fetal adrenal gland volume was $(\mathrm{AUC}=0.873)$. The ROC curve shows that the best cut off value using the volume was $\geq 0.461$ with $76.92 \%$ sensitivity and $88.24 \%$ specificity for prediction of preterm birth with an overall accuracy of $83.3 \%$ (Figure 1).

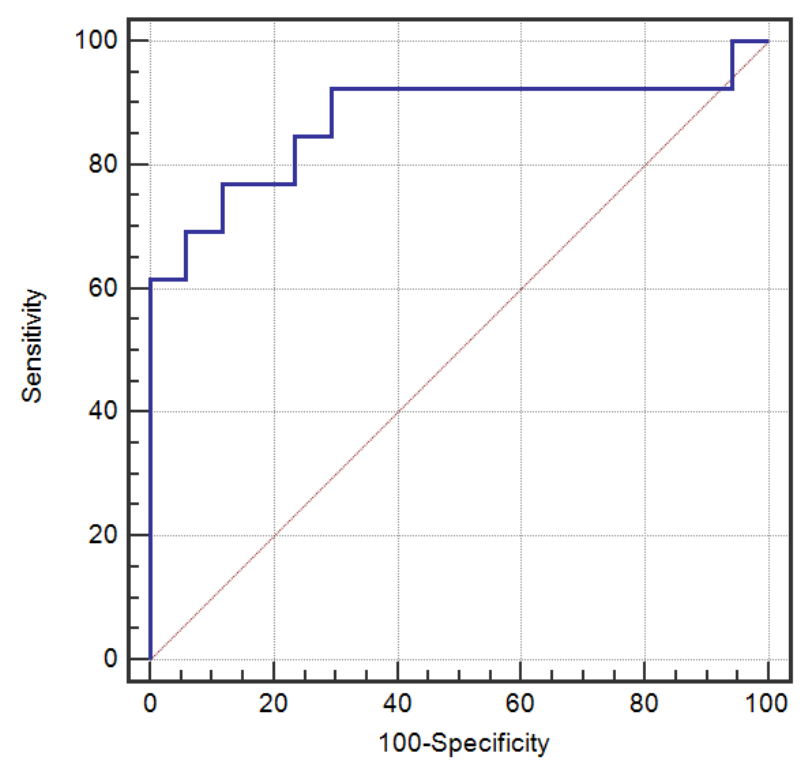

Figure 1: ROC curve analysis of the fetal adrenal gland volume for prediction of preterm birth.

\section{DISCUSSION}

This study is the second one, to the best of our knowledge, to test the hypothesis that the capacity of fetal adrenal artery Doppler velocimetry to predict delivery within 7 days for pregnant women with intact membranes in cases of spontaneous preterm birth and to compare these predictions with CL measurements and fetal adrenal gland volume. We assessed 30 singleton pregnancies and observe the change in fetal adrenal gland artery at time of Doppler in cases of preterm labour that delivered within 7 days and that delivered more than 7 days and compare with fetal adrenal volume.

In the current study, authors found that there was increase in fetal adrenal gland volume in preterm birth within 7 days that considered a direct positive relationship between fetal adrenal gland volume and preterm birth within 7 days. Our results agree with Turan et al and Guler et al who found that there was increase of fetal adrenal gland volume at the time of evaluation for symptoms of preterm birth. ${ }^{10,11}$

In contrast to present study Hoffman et al screened 128 women with symptom of preterm birth and rather than identifying enlarged adrenal glands associated with PTB they found that fetuses destined to deliver following preterm labor or preterm PPROM had significantly smaller adrenal glands. ${ }^{12}$ None of the fetal adrenal gland measurements distinguished spontaneous preterm birth from term birth.

In the current study, authors observed that both PI and RI were not good predictors of delivery within 7 days for pregnant women in cases of spontaneous preterm birth, in comparison with other obstetrical practice like cervical length measurement and fetal adrenal biometry 11 that have a greater predictive power for preterm birth in symptomatic pregnant women. ${ }^{13,14}$

In present study, there was no significant change in PI and RI of fetal adrenal gland artery at time of Doppler in cases that delivered within 7 days and that delivered more than 7 days in compare to fetal adrenal volume which have greater predictive power for preterm birth in symptomatic pregnant women in comparison with the previous study done by Carvalho et al who assessed 51 singleton pregnancies and observed that that the fetal adrenal artery reduces its resistance in cases of imminent preterm birth and both PI and RI were good predictors of delivery within 7 days for pregnant women in cases of spontaneous preterm birth. ${ }^{15}$

Present study had its limitations; firstly, single operator who evaluated all the cases and this limit the generalizability of the results. Additionally, the small sample size of included participants was another weak point. Further studies with large sample size us needed to confirm our results.

\section{CONCLUSION}

In conclusion, fetal adrenal gland volume was identified as a significant predictor of delivery in pregnant women who had spontaneous preterm births with intact membranes.

\section{Funding: No funding sources}

Conflict of interest: None declared

Ethical approval: The study was approved by the Institutional Ethics Committee 


\section{REFERENCES}

1. Marlow N, Wolke D, Bracewell MA, Samara M. Neurologic and developmental disability at six years of age after extremely preterm birth. New Eng J Med. 2005;352(1):9-19.

2. Hamilton BE, Martin JA, Ventura SJ, Sutton PD, Menacker F. Births: preliminary data for 2004. Natl Vital Stat Rep. 2005;54(8):1-17.

3. Lockwood CJ, Kuczynski E. Markers of risk for preterm delivery. J Perinat Med. 1999;27(1):5-20.

4. Norwitz ER, Robinson JN, Challis JR. The control of labor. New Eng J Med. 1999;341(9):660-6.

5. Challis JR. CRH. A placental clock and preterm labour. Nature Med.1999;1;1(5):416.

6. Langlois D, Li JY, Saez JM. Development and function of the human fetal adrenal cortex. J Pediat Endocrinol Metabol: JPEM. 2002;15:1311-22.

7. Anderson AM, Laurence KM, Davies K, Campbell $\mathrm{H}$, Turnbull AC. Fetal adrenal weight and the cause of premature delivery in human pregnancy. BJOG. 1971;78(6):481-8.

8. Goldenberg RL, Goepfert AR, Ramsey PS. Biochemical markers for the prediction of preterm birth. Am J Obstet Gynecol. 2005;192(5):S36-46.

9. ACOG. Practice bulletins No. 139: premature rupture of membranes. Obstet Gynecol. 2013;122(4):918-30.

10. Guler AE, Pehlivan H, Cakmak B, Baser I. Assessment of fetal adrenal gland enlargement in term and preterm labor cases. Int $\mathbf{J}$ Res Med Sci.2017;3(5):1035-40.
11. Turan OM, Turan S, Funai EF, Buhimschi IA, Campbell $\mathrm{CH}$, Bahtiyar $\mathrm{OM}$ et al. Ultrasound measurement of fetal adrenal gland enlargement: an accurate predictor of preterm birth. Am J Obstet Gynecol .2011;204(4):311-e1.

12. Hoffman Sage Y, Lee L, Thomas AM, Benson CB, Shipp TD. Fetal adrenal gland volume and preterm birth: a prospective third-trimester screening evaluation. J Maternal-Fetal Neonatal Med. 2016;29(10):1552-5.

13. Lim K, Butt K, Crane JM, Morin L, Bly S, Cargill Y, et al. Ultrasonographic cervical length assessment in predicting preterm birth in singleton pregnancies. J Obstetrics Gynaecol Canada. 2011;33(5):486-99.

14. Renzo GC, Rosati A, Mattei A, Gojnic M, Gerli S. The changing role of progesterone in preterm labour. BJOG. 2011;112(s1):57-60.

15. Carvalho FH, Lemos AP, Feitosa FE, Feitosa HN, Augusto LC, Mota RM, et al. Can fetal adrenal artery Doppler velocimetry predict delivery date in pregnant women with spontaneous preterm birth? Medical ultrasonography. 2017;19(3):295-301.

Cite this article as: Ali AS, Hussein M, Fetih AN, Ahmed AM, Abbas AM. Prediction of preterm birth by evaluating the fetal adrenal gland volume and blood flow: a pilot study. Int J Reprod Contracept Obstet Gynecol 2018;7:3906-10. 